This effort may involve retracing some of the steps in the move from work to text and observing how the text works-what kind of cultural labor it involves.

\section{ASTRADUR EYSTEINSSON} University of Iceland

I take this Forum topic to imply an opposition between cultural studies and the literary where cultural studies is a counterdisciplinary ethos of ideological unmasking that foregrounds mass-cultural, often nonverbal critical objects and where the literary is the object of an embattled but still academically entrenched high-cultural practice of textual celebration.

I believe it must follow from this distinction (but it is a problematic distinction) that literary studies will have given away all that can make ethical and institutional sense of its existence if the writerly nature of writers or the written nature of texts becomes incidental to the work of literature departments. If it is ever generally held true, for example, that authors simply exemplify their ideological moments unproblematically or stand as notable renegades against, or apologists for, cultural structures, the study of authors will be tantamount to the study of significant celebrities or instructive nobodies, made available to study through procedures of historical recovery that could issue from any number of academic quarters-history, women's studies, anthropology, and so on. Of course, such studies can be inspiring and thoughtprovoking, even though they do not hinge on, and sometimes do not even credit, any specifically literary quality of their objects. But they are not invested in a conception of the literary.

Nevertheless, I do not consider the trend toward cultural studies and away from procedures of rhetorical exegesis a serious problem for literary studies. Now more than ever, any elaborated or ideologically specific description of what might be "generally held true" about literary studies is likely to prove inadequate or even deluded. Academic trends take place within a matrix of varied practices, and no single trend can constitute that matrix. As an academic enterprise in literature departments, cultural studies makes little sense without the literary, and the literary makes little or no sense without cultural studies, a conclusion analogous to the one implied by the letters on interdisciplinarity in the Forum last year (111 [1996]: 271-311).

It would be foolish, however, to say that the urgency this debate has assumed is illusory. In some of the contest's more fully articulated forms, a principled antagonism can take shape between partisans identifying with these two modes of scholarship — say, during faculty hir- ing. But it seems to me that such a dispute would not turn fundamentally on an antithesis of critical enterprises. A better explanation lies in the anxiety-provoking economics of scarcity within higher education, which forces intractably the question of who will populate and lend shape to each venue of literary academia (department, journal, conference) at a time when there is not necessarily a place for every person, every voice. Like travelers stranded in a storm with inadequate food and shelter, academics may rashly direct their frustration at their fellows. How to assess and manage a finite and even dwindling environment is the imposing question.

In contexts where any broad articulation of literature is at issue, such as a department that must serve the needs of students and a community, an inclusive and affirmative notion of critical diversity has more-urgent claims than does either cultural studies or a scholarship of the literary. Curiously, departments might well say of critical enterprises, "United we fall."

\section{DAVID WAYNE THOMAS \\ University of Michigan, Ann Arbor}

Despite the speed at which its projects are multiplying, cultural studies continues to find itself, or reach critical self-awareness, at the limits of the literary. Of course, these limits too are manifold and slippery, as befits an institution that instantiates what Derrida once dubbed "the drama" of indeterminate destinations (Les fins de I'homme: A partir du travail de Jacques Derrida (Paris: Gatilée, 19811214). But whatever criteria one uses to identify the literary, it is clear that in recent years its semiotic destinations have become ever more uncertain. Enter cultural studies, stage left.

In the broadest historical terms, cultural studies can be read as a response to two interlinked developments affecting literary discourse. On the one hand, the literary has tended to become increasingly specialized, so that typically literature now refers-as it once did not-to the forms of imaginative writing with uniquely creative or aesthetic value: the poem and the novel, say, and not biography or the essay. Many of the current preoccupations of literary criticism continue to take their point from this shift: hence the various attempts to valorize and defend a canon or the ongoing investigations into "literariness," the distinctive properties of literary language. On the other hand, literature has been massively displaced, squeezed on all sides by the new electronic media, and it is often represented-often represents itself-as under siege. Writers may try to claim that literature retains a privileged role in the production of their cultures' key narratives, but this last-ditch stand only un- 